ARTICLE

\title{
Power grid with $100 \%$ renewable energy for small island developing states
}

\section{Nexus of energy, environment, and economic growth}

\author{
Yuichi lkeda ${ }^{1}$ (D)
}

Published online: 21 August 2019

(c) The Author(s) 2019

\begin{abstract}
We estimated system-wise levelized cost of electricity (LCOE) for a power grid with a high level of renewable energy using our grid optimization model. The estimation results of the system-wise LCOE are discussed in terms of the nexus of energy, environment, and economic growth for Small Island Developing States (SIDS) economies. While $100 \%$ renewable energy is technologically possible with the usage of electricity storage, the estimated LCOE is as high as 397 \$/MWh which is substantially higher than electricity prices for residential consumers in the US and Japan. The susceptibility analyses imply that the estimated LCOE increase of $223 \%$ with a $100 \%$ renewable power grid corresponds to an as high as $11 \%$ decrease in economic growth. This decrease in economic growth would have a significant negative impact on SIDS economies. However, hydrogen production via the electrolysis of water using the excess energy supply from solar photovoltaics would reduce the LCOE, and therefore, higher economic growth would be attained with less $\mathrm{CO}_{2}$ emission.
\end{abstract}

Keywords Energy · Power grid · Renewable energy $\cdot$ Levelized cost of electricity · Economic growth

JEL Classification Q40 · F43 · Q50

\section{Introduction}

The population size of Small Island Developing States (SIDS) is rather limited. SIDS have a combined population of approximately 65 million (UN-OHRLLS 2015 ), which is approximately $1 \%$ of the world's population. In SIDS, nearly $30 \%$ of

Yuichi Ikeda

ikeda.yuichi.2w@kyoto-u.ac.jp

1 Graduate School of Advanced Integrated Studies in Human Survivability, Kyoto University, 1

Yoshida-Nakaadachi-cho, Sakyo-ku, Kyoto-shi, Kyoto 606-8306, Japan 
the population lives at elevations of less than $5 \mathrm{~m}$ above sea level. Therefore, SIDS are often said to be the most vulnerable areas to climate change due to the currently increasing $\mathrm{CO}_{2}$ emissions.

The Intergovernmental Panel on Climate Change (IPCC) has reported that emissions resulting from human activities are substantially increasing atmospheric concentrations of greenhouse gases, resulting on average in additional warming to the Earth's surface (IPCC 1990). Based on IPCC reports, policy makers in various countries, including advanced countries, emerging economies, and SIDS, have proposed energy policies to introduce as much renewable energy as possible to curtailing $\mathrm{CO}_{2}$ emissions. However, skepticism persists due to the high cost of investment in renewable energy and its integration into power grids.

Here, we briefly review the sustainable development goals (SDGs) (Sachs 2015) and discuss the synergy and trade-off between these goals. The SDGs consists of 17 goals and 169 targets. Some targets are common to different goals. Le Blanc expressed the SDGs as a bipartite network between the 17 goals and 169 targets (Le Blanc 2015). Contracting the bipartite network, we obtain a network that only consists of targets. The links of the obtained network are weighted, even though the links of the original bipartite network are binary. Many high degree nodes are located at the center of the network, e.g., SDG 1 "poverty", SDG 10 "inequality", SDG 12 "sustainable consumption and production", and SDG 8 "growth and employment". The synergy between SDGs is identified as pairs of nodes connected by large weight links, e.g., SDG 1 "poverty" and SDG 10 "inequality", SDG 5 "gender" and SDG 4 "education", and SDG 16 "peaceful and inclusive" and SDG 10 "inequality". Conversely, trade-off between SDGs is identified as pairs of nodes without link, e.g., SDG 7 "energy" and SDG 13 "climate change".

Here, we point out the need for a concrete example studying the trade-off between energy goals and climate change. In this paper, we consider a power grid with high rate of renewable energy in SIDS economy, and discuss nexus of energy, environment, and economic growth. The goal of this paper is to estimate the electricity price for a power grid with high rate of renewable energy for an SIDS economy and to discuss how the estimated electricity price affects the economic growth. This paper is organized as follows. In Sect. 2, a model of grid integration of renewable energy is described. In Sect. 3, the detail of our analysis is explained. In Sect. 4, various results are shown and discussion on nexus of energy, environment, and economic growth for a SIDS economy is given. Section 5 summarizes the paper.

\section{Grid integration of renewable energy}

Our model of grid integration for renewable energy is described in this section (Ikeda and Ogimoto 2014; Kimura et al. 2015, 2018). We assume here that the thermal power plants in an SIDS economy consist primarily of diesel power, i.e., less coal and natural gas thermal power. We also assume that the renewable energy in SIDS economy is mainly solar photovoltaic (PV), i.e., less wind power, because the 
low altitude area where most SIDS are located are rich in solar potential and poor in wind potential (Chatzivasileiadis et al. 2013).

\subsection{Power grid}

A typical conventional power grid today includes thermal power plants on the supply side and also factories, office buildings, and individual residences on the demand side. The demand varies and fluctuates with time. This fluctuation needs to be balanced by changing the output of the thermal power plants (International Energy Agenvy 2018).

The evolution of power grids is currently underway and moving toward the first phase of smart grid. Solar PV panels are starting to be installed in various locations on power grids on both the supply and demand sides. The installation of renewable energy introduces additional fluctuation into a power grid. This requires additional balancing power, even though the demand for electricity on the supply side decreases due to the additional capacity of the renewable energy on the supply side. Therefore, we need a certain capacity of electricity storage to obtain sufficient balancing power for the stable operation of the power grid. Currently, the cost of electricity storage is high: therefore, the price of electricity must increase.

In the near future, demand-side management systems which consist of a smart meter, a home energy management server, and appliances applicable to the server, will become popular and we will obtain a new source of balancing power on the demand side. This new balancing power will reduce the capacity of the electricity storage required to balance fluctuations in the renewable energy. We call the second phase of the smart grid. However, it might be delayed to diffuse the technology of the second phase of smart grid, primarily due to the complicated relationships between power grid stakeholders.

Our grid model aims to describe the first phase of a smart grid to estimate the electricity price for a power system with a high level of renewable energy integration in an SIDS economy.

\subsection{Grid model}

We formulate our grid model as an optimization model. The concept of our grid model is shown in Fig. 1. First, we define the objective function which is equal to the fuel expenditure required to operate the thermal power plants:

$$
\sum_{t=1}^{T} \sum_{i=1}^{N} b_{i} p_{t}^{i},
$$

where $b_{i}$ is the fuel cost used to obtain a unit of electricity from a thermal power plant $i$ and $p_{t}^{i}$ is the output electricity at a time $t$ from the plant $i . T$ and $N$ are the time period of the calculation and the number of thermal power plants, respectively. 


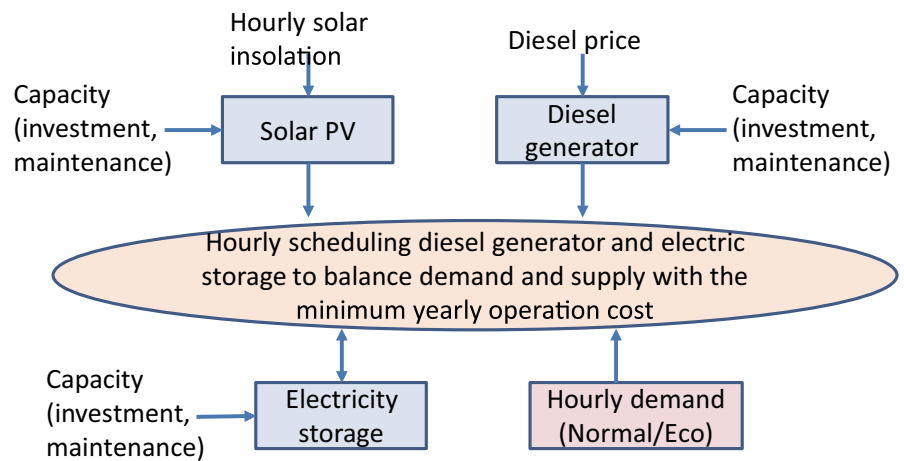

Fig. 1 Concept of our grid model. The model is formulated using Eqs. (1)-(6)

In this paper, the time period is 1 year and the time step is $1 \mathrm{~h}$, and therefore, $T=24 \times 365=8760$.

The objective function in Eq. (1) is minimized under the global constraints of the demand-supply balance and some local constraints on the electricity storage. The global constraints of the demand-supply balance are given as follows:

$$
\frac{\sum_{i=1}^{N} p_{t}^{i}+\mathrm{pv}_{t}^{(f)}+g_{t}-h_{t}-d_{t}^{(f)}}{\sqrt{\sigma_{d}^{2}+\sigma_{p}^{2}}} \geq \phi^{-1}(\alpha),
$$

where $\mathrm{pv}_{t}^{(f)}, g_{t}, h_{t}, d_{t}^{(f)}, \sigma_{d}^{2}$, and $\sigma_{p}^{2}$ are the solar PV output forecast at $t$, the discharged electricity from the electricity storage at $t$, the electricity charged to storage at $t$, the demand forecast at $t$, the variance of the demand fluctuation, and the variance of the fluctuation in the solar PV output, respectively. Note that the fluctuations of the demand and renewable energy are stochastically taken into account. $\alpha$ and $\phi(\alpha)$ are the probability of ensuring the supply-demand balance and the cumulative distribution function, respectively. In this paper, we use $\alpha=1.28$, which means that the demand-supply balance is satisfied with a probability of $90 \%$. The cumulative distribution function is written using the error function $\operatorname{erf}[\cdot]$ as follows:

$$
\phi(x)=\frac{1}{2}\left(1+\operatorname{erf}\left[\frac{x-\mu}{\sqrt{2 \sigma^{2}}}\right]\right) .
$$

Here, $\mu=0$ and $\sigma=1$, because the left-hand side of Eq. (2) is normalized. The local constraints on the electricity storage are given as follows:

$$
\begin{gathered}
v_{t} c_{\min } \leq g_{t} \leq v_{t} c_{\max }, \\
\left(1-v_{t}\right) c_{\min } \leq h_{t} \leq\left(1-v_{t}\right) c_{\max }, \\
R_{\min } \leq \sum_{s=1}^{t}\left(h_{s} \eta-g_{s}\right) \Delta_{t} \leq R_{\max },
\end{gathered}
$$


where $v_{t}, c_{\min }, c_{\max }, R_{\min }, R_{\max }, \eta$, and $\Delta_{t}$ are the state variable of the electricity storage $\left(v_{t}=1\right.$ : discharge, $v_{t}=0$ : charge), minimum discharge power, maximum discharge power, minimum stored energy, maximum stored energy, efficiency, and time step, respectively.

Next, we describe the system-wise levelized cost of electricity (LCOE). The system-wise LCOE is estimated by including the thermal power plants, solar PV, and electricity storage. Therefore, the system-wise LCOE is interpreted as a measure of the electricity price, even though the cost of transmission and distribution and the profit of the utility company are not included. The system-wise LCOE is defined by the aggregated expenditure (\$) to supply a unit amount of electricity (MWh) to the consumer:

$$
\begin{gathered}
\mathrm{LCOE}=\frac{\sum_{y=1}^{Y} \frac{I_{y}+M_{y}+F_{y}}{(1+r)^{y}}}{\sum_{y=1}^{Y} \frac{E_{y}}{(1+r)^{y}}}, \\
E_{y}=\sum_{i=1}^{N} P_{y}^{i}+P V_{y}^{(f)}+G_{y}-H_{y} \\
P_{y}^{i}=\sum_{t=1}^{T} p_{t}^{i}, \\
P V_{y}^{(f)}=\sum_{t=1}^{T} p v_{t}^{(f)}, \\
H_{y}=\sum_{t=1}^{T} h_{t}, \\
G_{y}=\sum_{t=1}^{T} g_{t},
\end{gathered}
$$

where $I_{y}, M_{y}, F_{y}, r$, and $T$ are the investment expenditures (including finance) in year $y$, the operation and maintenance expenditures in year $y$, the fuel expenditures in year $y$, the discount rate, and the life of the system, respectively. Note that $I_{y}$ and $M_{y}$ are aggregated for all of the thermal power plants, renewable energy, and electricity storage on the supply side. Conversely, $F_{y}$ is only aggregated for all of the thermal power plants. $P_{y}^{i}, P V_{y}^{(f)}, G_{y}$, and $H_{y}$ in Eqs. (7)-(12) are sum of $p_{t}^{i}, p v_{t}^{(f)}, g_{t}$, and $h_{t}$ calculated in Eqs. (1)-(6) for 1 year, respectively, and are assumed as constant values during the life of system $Y$. 


\section{Analysis conditions}

We assume a representative case to analyze a power grid with a high level of renewable energy in an SIDS economy. The details of the analysis conditions for a representative case are explained in this section.

\subsection{Representative case}

We quantitatively estimated electricity prices for power grids in the Temburong area of Brunei with different share of renewable energy using the grid model described in Sect. 2.2. Even though Brunei is not categorized as a SIDS area in a precise sense, the Temburong area is an isolated enclave of Brunei and its geographical and demographical conditions are similar to many SIDS area. For this reason, we assume that the Temburong area is equivalent to SIDS in terms of power grid analysis.

Time series of the solar radiation in Brunei are shown in Fig. 2 for January, 2016. Each line corresponds to the temporal change in the solar radiation from 6:00 am to 20:00 pm on a single day. Figure 2 shows that the fluctuation can be considerable depending on the weather conditions, e.g., the coefficient of variation is $28 \%$ at noon.

The estimated electricity demand is shown in Fig. 3 for a weekday and a weekend day. The first $24 \mathrm{~h}$ shows the demand for a weekday, and the last $24 \mathrm{~h}$ shows that for a weekend day. The shape of the estimated electricity demand is fairly flat during the daytime and shows peaks in the early evening. The demand on a weekend day is considerably lower than the demand on a weekday. The blue curve and red curve are the normal demand and the eco-demand, respectively. Here, the eco-demand is estimated for energy-saving buildings. The peak of the ecodemand is approximately $78 \%$ that of the normal demand. A detailed description of this demand estimation is given in Ref. Kimura et al. (2018).

Fig. 2 Time series of the solar radiation in Brunei. Each line corresponds to the temporal change in the solar radiation from 6:00 am to 20:00 pm in a single day

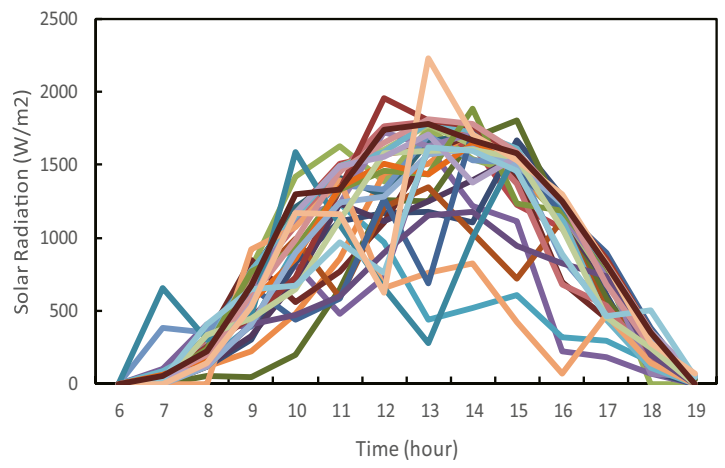


Fig. 3 Estimated electricity demand for a weekday and a weekend day. The eco-demand is estimated for energy-saving buildings. A detailed description of the demand estimation is given in Ref. Kimura et al. (2018)

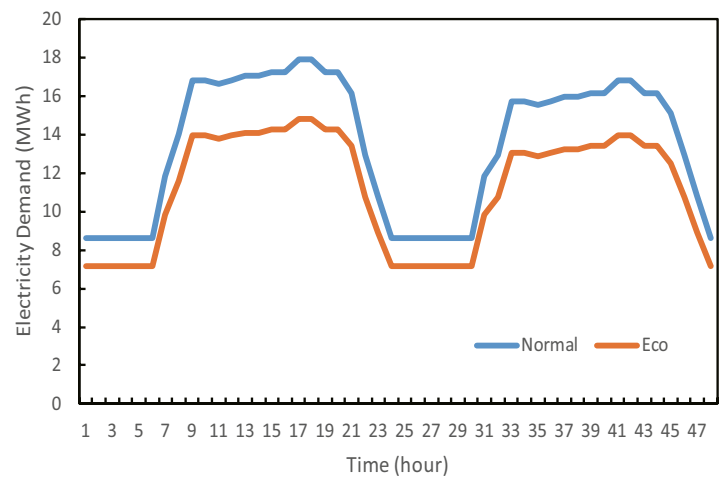

\subsection{Parameters on the supply side}

The parameters for the diesel generators are shown in Table 1. The number of diesel generators $N$ changes over the range of $0-7$. We assume that the diesel fuel price in Brunei is $1 / 3$ the price in the US. Note, however, that this assumption might not be valid for all SIDS economies. We simply use this assumption to provide a generic value in this representative case. In addition, when estimating the road factor of the diesel generators, we assume that the 3-month maintenance is scheduled after 1 year of generator operation.

The solar PV parameters are shown in Table 2. The installed solar PV capacity varies in the range of $0.0-192.0(\mathrm{MW})$. Note that the initial investment cost 1500

Table 1 Parameters of diesel generator

\begin{tabular}{ll}
\hline Parameter & Value \\
\hline Fuel price (\$/litter) (Diesel price in Brunei, 1/3 of US) & 0.32 \\
Rated power (MW) & 3.0 \\
Road factor (3 months maintenance after 1 year operation) & 0.8 \\
Initial investment cost (\$/kW) & 650 \\
Operation and maintenance cost (\$/MW/year) & $15 \times 1000$ \\
\hline
\end{tabular}

Table 2 Parameters of solar PV

\begin{tabular}{ll}
\hline Parameter & Value \\
\hline Installed capacity $(\mathrm{MW})$ & $0.0-192.0$ \\
Rated power of unit module $(\mathrm{MW})$ & 6.0 \\
Road factor & 0.18 \\
Initial investment cost $(\$ / \mathrm{kW})$ & $1500(\mathrm{Genera}-$ \\
& tion cost $5 \mathrm{c} /$ \\
& $\mathrm{kWh})$ \\
Operation and maintenance cost $(\$ / \mathrm{MW} /$ year $)$ & $15 \times 1000$ \\
\hline
\end{tabular}


Table 3 Parameters of electricity storage

\begin{tabular}{ll}
\hline Parameter & Value \\
\hline Minimum discharge power (MW) & 0.0 \\
Maximum discharge power (MW) & $0.0-95.0$ \\
Minimum electricity storage capacity (MWh) & 0.0 \\
Maximum electricity storage capacity (MWh) & $0.0-570.0$ \\
Efficiency & 0.7 \\
Initial investment cost $(\$ / \mathrm{kWh})$ & 200 \\
\hline
\end{tabular}

$\$ / \mathrm{kW}$ corresponds to the generation cost $5 \mathrm{c} / \mathrm{kWh}$. This means that the generation cost of solar PV is not excessive today. The load factor 0.18 is relatively high for the solar PV generation. We assume that this value is plausible for most SIDS economies, because most SIDS are located at low latitudes.

The electricity storage parameters are shown in Table 3. Here, we consider battery-type electricity storage, such as Li-ion batteries, NaS batteries, lead acid batteries, and vanadium redox flow batteries. We assume a proportionality between the maximum discharge power $x(\mathrm{MW})$ and the maximum stored electricity $6 \cdot x$ (MWh). Even though the efficiency 0.7 varies depending on the technology used for the storage, we use this as a generic value.

For the LCOE estimation in Eq. (7), we assume a life of system of $Y=20$ (years) and a discount rate of $r=0.05$. Note that the fuel expenditures $F_{y}$ and the electricity generation $E_{t}$ calculated by aggregating the results of the optimization of our grid model described in Sect. 2.2 at an hourly time step over 1 year are used throughout the 20 years of the life of the system.

\section{Results and discussion}

The estimation results for the grid operation and system-wise LCOE using the grid model described in Sect. 2.2 are shown and discussed in terms of the nexus of energy, environment, and economic growth for an SIDS economy in this section.

\subsection{Results}

The electricity from diesel generators which is required to satisfy a given demand was estimated throughout a year with a given output from the solar PV of $12 \mathrm{MW}$. Five diesel generators and a maximum electricity storage capacity of $30 \mathrm{MWh}$ are required on the supply side to satisfy the normal demand throughout a year. The estimation results for the electricity supply on a weekday and a weekend day in January are shown in Fig. 4. Here, the given electricity demand is indicated by a red curve for a weekday and a weekend day. The number of diesel generators is reduced from seven to five using a maximum electricity storage capacity of $30 \mathrm{MWh}$. In Fig. $4, p_{t}^{1}$ $-p_{t}^{5}$ show the outputs of the five diesel generators, $h_{t}$ shows the excess output from solar PV charged into the electricity storage, and $g_{t}$ shows the discharged electricity. 


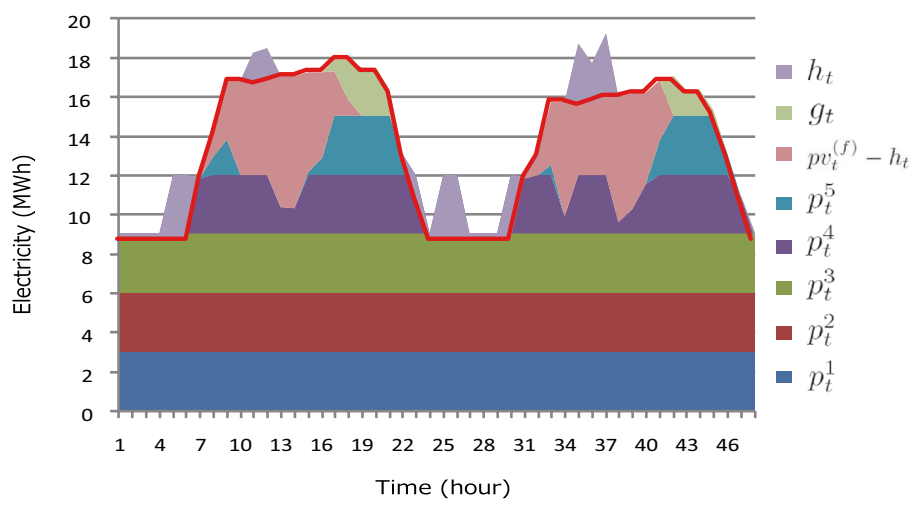

Fig. 4 Electricity supply on a weekday and a weekend day in January. The electricity demand is indicated by a red curve for a weekday and a weekend day. $p_{t}^{1}-p_{t}^{5}$ show the outputs of the five diesel generators. $h_{t}$ shows the excess output from solar PV charged into the electricity storage, and $g_{t}$ shows the discharged electricity

The estimated system-wise LCOEs are shown in Fig. 5 as a function of the solar PV and electricity storage capacities for the eco-demand case. The white area in Fig. 5 indicates that the optimization described in Sect. 2.2 is not feasible for the specified solar PV and electricity storage capacities. For the systems in panel (a), the installed diesel generator and solar PV capacities are $12 \mathrm{MW}$ and $6 \mathrm{MW}$, respectively. The maximum stored electricity is $48 \mathrm{MWh}$, and the lowest system-wise LCOE is estimated to be $123 \$ / \mathrm{MWh}$. For the systems in panel (b), the installed diesel generator and solar PV capacities are $6 \mathrm{MW}$ and $72 \mathrm{MW}$, respectively, the maximum stored electricity is $180 \mathrm{MWh}$, and the lowest system-wise LCOE is estimated to be $245 \$ / \mathrm{MWh}$. For the systems in panel (c), the install diesel generator and solar PV capacities are $0 \mathrm{MW}$ and $120 \mathrm{MW}$, respectively, the maximum stored electricity is $450 \mathrm{MWh}$, and the lowest system-wise LCOE is estimated to be 397 / $\mathrm{MWh}$. The 12-MW and 0-MW diesel generator cases correspond to the business-asusual scenario and the $100 \%$ renewable energy scenario, respectively. While $100 \%$ renewable energy, i.e., no diesel generator, is technologically possible with the usage of electricity storage, the estimated LCOE is 397 \$/MWh. Note that this estimated LCOE is substantially higher than electricity prices for residential consumers in the US (125 \$/MWh) and Japan (253 \$/MWh) (International Energy Agency 2015).

\subsection{Discussion}

The nexus of energy, environment, and economic growth are discussed here to provide invaluable insights toward the realization of SDGs. The susceptibility analyses of the electricity price on the economic growth can be broken down into two stages. The first stage is an analysis of the relationship between the electricity demand and the economic growth. The second stage is an analysis of the price elasticity of the demand for electricity.

Studies in the first stage can be summarized as follows. 
(a) $12 \mathrm{MW}$ diesel generators

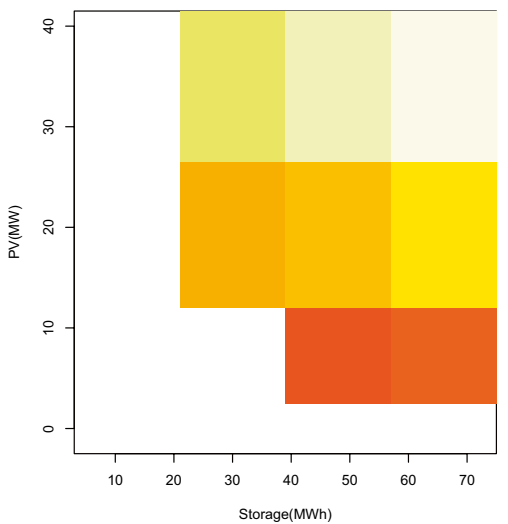

(c) No diesel generator

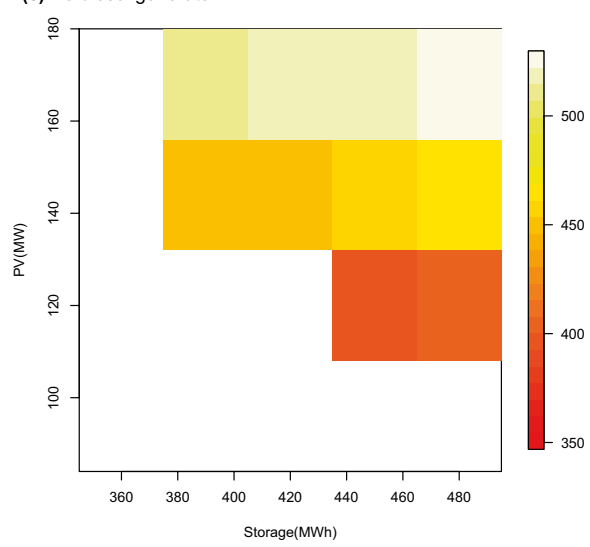

(b) $6 \mathrm{MW}$ diesel generators

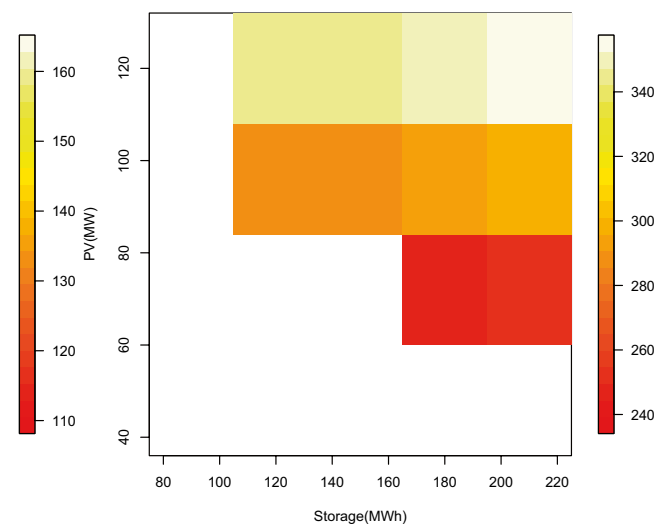

Fig. 5 System-wise LCOE as a function of the solar PV and electricity storage capacities for the ecodemand case. The white area indicates that the optimization is not feasible for the specified solar PV and the electricity storage capacities. The lowest system-wise LCOEs are 123 \$/MWh, $245 \$ / M W h$, and 397 $\$ / M W h$ in panel $\mathbf{a}, \mathbf{b}$, and $\mathbf{c}$, respectively

- In 17 Taiwanese industries, a study of electricity consumption and economic growth indicated that a $1 \%$ increase in the electricity consumption is accompanied with growth of the real GDP by $1.72 \%$ (Lu 2017).

- In China, from 1950 to 1980 , the elasticity of electricity consumption on economic growth was increased from 2.33 to 2.72 which is significantly greater than 1. From 1990 to 2013 , the growth rate of the electricity consumption was highly correlated with change in the GDP growth (Zhanga et al. 2017).

- In the US, the electricity consumption growth and GDP growth occurred at a similar rate from 1949 to 1996: however, from after 1996 to today, this correlation gradually decreased (Hirsh and Koomey 2015). This change might have been caused by structural changes in US industries toward the digital economy.

The studies in the second stage can be summarized as follows. 
- In the US, the estimated long-run price elasticity of the demand for commercial electricity varied from -3.11 to -0.497 depending on the states(Bernstein and Griffin 2006). The average elasticity was -1.43 . Conversely, estimated long-run price elasticity of the demand for residential electricity varied from -0.618 to -0.058 . The average elasticity was -0.282 .

- In East Asia, an analysis of the long-run price elasticity of energy consumption, which is slightly different from electricity consumption, during 2000 and 2010 showed that the elasticity was $+0.212,-0.125,+0.212,-0.0837,-0.343$, -0.997 , and +4.17 for Australia, Japan, China, India, Philippines, Thailand, and Singapore, respectively (Phoumin and Kimura 2014). The average was -0.188 : here, Singapore was excluded from the average.

The first-stage studies show that correlations between the electricity demand and economic growth are very high. Therefore, we assume that the generic value of the correlation is approximately 1.0. The second stage studies show that the price elasticity of the demand for electricity is a small negative value. Therefore, we assume that the generic value of the elasticity is approximately -0.05 . The susceptibility analyses of the electricity price on the economic growth indicate that a $1 \%$ increase in electricity prices is associated with an approximately $0.05 \%$ decrease in economic growth. This assumption was confirmed by a study on the impact of electricity price on economic growth in South Africa (Khobai et al. 2017). This study showed that a $1 \%$ increase in electricity prices caused the economic growth to drop by $0.036 \%$. We adopt the assumption that a $1 \%$ increase in electricity prices is associated with an approximately $0.05 \%$ decreases in economic growth for SIDS economies. These analyses imply that the estimated LCOE increases of $223 \%(=(397-123) / 123)$ for the $100 \%$ renewable power grid corresponds to an as high as $11 \%$ decrease in economic growth. This decrease would result in significant negative impacts for a SIDS economy.

The estimated high LCOE is primarily due to the high initial investment cost of the electricity storage shown in Table 3 . Therefore, we need an innovation to permit the installation of electricity storage with a low initial investment cost. For example, grid-to-vehicle $(\mathrm{G} 2 \mathrm{~V})$ and vehicle-to-grid (V2G) technologies might provide an additional capacity of the electricity storage with a low cost (Heinen et al. 2011), or alternatively, excess solar PV supply could be used to produce hydrogen via the electrolysis of water (Hosseini and Wahid 2016; International Renewable Energy Agency 2018). The produced hydrogen could then be stored in a hyperbaric chamber. Hydrogen combustion in gas turbines would reduce fuel consumption, and as a result, it would be possible to curtail $\mathrm{CO}_{2}$ emissions. This would make it possible to reduce the electricity storage capacity needed to balance the supply and demand. Consequently, a lower LCOE and, therefore, a higher economic growth would be attained with less $\mathrm{CO}_{2}$ emissions (International Energy Agenvy 2019). 


\section{Summary}

We estimated the system-wise LCOE for a power grid with a high level of renewable energy to discuss how the estimated LCOE affects the economic growth in a SIDS economy.

Our grid model aims to describe the first phase of smart grid to estimate the electricity price for a power system with a high level of renewable energy integration in an SIDS economy. We formulated our grid model as an optimization model. The objective function was minimized under the global constraints of the demand-supply balance and some local constraints on the electricity storage.

We quantitatively estimated a measure of the electricity price for power grids in an SIDS economy. The estimation results of the system-wise LCOE using the grid model were discussed in terms of the nexus of energy, environment, and economic growth on an SIDS economy. While $100 \%$ renewable energy is technologically possible with the usage of electricity storage, the estimated LCOE is as high as 397 \$ MWh. This estimated LCOE is substantially higher than electricity prices for residential consumers in the US (125 \$/MWh) and Japan (253 \$/MWh).

Susceptibility analyses in South Africa, China, and the US show that a $1 \%$ increase in electricity prices is associated with an approximately $0.05 \%$ decrease in economic growth. These analyses imply that the estimated cost increase of $223 \%$ with a $100 \%$ renewable power grid corresponds to an as high as $11 \%$ decrease in economic growth. This decrease in economic growth would result in significant negative impact on SIDS economies.

The obtained high LCOE is primarily due to the high initial investment cost of the electricity storage. Therefore, we need an innovation to allow the use of electricity storage with a low initial investment cost. For example, the excess solar PV supply could be used to produce hydrogen via the electrolysis of water. The produced hydrogen could be stored in a hyperbaric chamber. Hydrogen combustion in gas turbines would reduce the consumption of diesel fuel, and as a result, it would be possible to curtail $\mathrm{CO}_{2}$ emissions. This would make it possible to reduce the electricity storage capacity required to balance the supply and demand. Consequently, a lower LCOE and, therefore, higher economic growth would be attained with less $\mathrm{CO}_{2}$ emissions.

Acknowledgements The author would like to thank Shigeru Kimura (Economic Research Institute for ASEAN and East Asia), Han Phoumin (Economic Research Institute for ASEAN and East Asia), Romeo Pacudan (Brunei National Energy Research Institute), Muhammad Nabih Fakhri Matussin (Brunei National Energy Research Institute), Majid Haji Sapar(Brunei National Energy Research Institute), Lam Kim Seong (Prudenergy Consulting Private Ltd.), Leong Siew Meng (Green Tech Solutions Inc.), and Takayuki Kusajima (Toyota Motor Corporation) for valuable comments.

Funding The present study was supported by the Ministry of Education, Science, Sports, and Culture, Grants-in-Aid for Scientific Research (B), Grant no. 17KT0034 (2017-2019) and Exploratory Challenges on Post-K computer (Studies of Multi-level Spatiotemporal Simulation of Socioeconomic Phenomena).

\section{Compliance with ethical standards}

Conflict of interest Author declares that he has no conflict of interest. 
Ethical approval This article does not contain any studies with human participants or animals performed by any of the authors.

Open Access This article is distributed under the terms of the Creative Commons Attribution 4.0 International License (http://creativecommons.org/licenses/by/4.0/), which permits unrestricted use, distribution, and reproduction in any medium, provided you give appropriate credit to the original author(s) and the source, provide a link to the Creative Commons license, and indicate if changes were made.

\section{References}

Bernstein MA, Griffin J (2006) Regional differences in the price-elasticity of demand for energy. NREL/ SR-620-39512

Chatzivasileiadis S, Ernst D, Andersson G (2013) The global grid. Renew Energy 57:372-383

Heinen S, Elzinga D, Kim S-K, Ikeda Y (2011) Impact of smart grid technologies on peak load to 2050. International Energy Agency, Working Paper, OECD Publishing

Hirsh RF, Koomey JG (2015) Electricity consumption and economic growth: a new relationship with significant consequences? Electr J 28(9):72-83

Hosseini SE, Wahid MA (2016) Hydrogen production from renewable and sustainable energy resources: promising green energy carrier for clean development. Renew Sustain Energy Rev 57:850-866

Ikeda Y, Ogimoto K (2014) Cross-correlation of output fluctuation and system-balancing cost in photovoltaic integration. J Eng 2014:1-9. https://doi.org/10.1049/joe.2014.0235

International Energy Agency (2015) Energy Prices and Taxes quarterly, 4th Quarter

International Energy Agency (2018) Part B: special focus on electricity. In: World Energy Outlook 2018

International Energy Agency (2019) The future of hydrogen, seizing today's opportunities

International Renewable Energy Agency September (2018) Hydrogen from renewable power: technology outlook for the energy transition

IPCC (1990) IPCC 1990 first assessment report overview chapter

Khobai HB, Mugano G, Le Roux P (2017) The impact of electricity price on economic growth in South Africa. Int J Energy Econ Policy 7(1):108-116

Kimura S, Matussin MNF, Meng LS, Ikeda Y (2018) Simulation study on energy mix for power generation in Temburong eco town. ERIA Research Project Report 2017, No. 02, chapter 3

Kimura S, Pacudan R, Phoumin H, Matussin MNF, Sapar MH, Seong LK, Meng LS, Kusajima T, Ikeda Y (2015) Development of the eco town model in the ASEAN region through adoption of energyefficient building technologies, sustainable transport, and smart grids. ERIA Research Project Report 2015, No. 20, chapter 4

Le Blanc D (2015) Towards integration at last? The sustainable development goals as a network of targets. DESA Working Paper No. 141

Lu W (2017) Electricity consumption and economic growth: evidence from 17 Taiwanese Industries. Sustainability 9:50. https://doi.org/10.3390/su9010050

Phoumin H, Kimura S (2014) Analysis on price elasticity of energy demand in East Asia: empirical evidence and policy, implications for ASEAN and East Asia. ERIA-DP-2014-05

Sachs JD (2015) The age of sustainable development. Columbia University Press, New York

UN-OHRLLS (2015) SIDS in numbers climate change edition 2015

Zhanga C, Zhoua K, Yanga S, Shaoa Z (2017) On electricity consumption and economic growth in China. Renew Sustain Energy Rev 76:353-368

Publisher's Note Springer Nature remains neutral with regard to jurisdictional claims in published maps and institutional affiliations. 